\title{
SECURITY AND SAFETY MANAGEMENT AND ROLE OF LASER SCANNING IN UNIQUE AND PECULIAR CULTURAL HERITAGE SITES SUCH AS THE PAPAL BASILICA AND THE SACRED CONVENT OF SAINT FRANCIS IN ASSISI IN ITALY
}

\author{
FABIO GARZIA $^{1,2,3,4}$, DOMENICA COSTANTINO ${ }^{5} \&$ VALERIO BAIOCCHI $^{6}$ \\ ${ }^{1}$ Safety \& Security Engineering Group - DICMA, SAPIENZA - University of Rome, Italy \\ ${ }^{2}$ Wessex Institute of Technology, Southampton, UK \\ ${ }^{3}$ European Academy of Sciences and Arts, Salzburg, Austria \\ ${ }^{4}$ Foundation for the Basilica of Saint Francis in Assisi, Assisi, Italy \\ ${ }^{5}$ DICEA, SAPIENZA - University of Rome, Italy \\ ${ }^{6}$ DICATECh, Politecnico di Bari, Italy
}

\begin{abstract}
Peculiar, unique and complex cultural heritage sites, such as the Papal Basilica and the Sacred Convent of Saint Francis in Assisi in Italy, need a great effort to ensure visitors security and safety, cultural heritage preservation and protection and great usability for visitors with particular reference to visitors with disabilities and for all the people and personnel normally present for the site management.

This goal can be reached using integrated systems and new technologies, such as Internet of Everything (IoE), which allows to connect people, things (mobile terminals, smart sensors, devices, actuators, wearable devices, etc.), data/information/knowledge and processes to reach the desired purposes.

The IoE system must be able to implement and support an integrated multidisciplinary model for security and safety management (IMMSSM) for the specific context, using a multidisciplinary approach.

Because of the plenty of data and information necessary to produce a proper IMMSSM which allows the consequent design and realization of the related IoE system, it is necessary to have detailed and accurate information about the architectural aspects of this wide, complex and peculiar site that only a proper laser scanning activity allows.

The purpose of this article is to illustrate the methodology and the results obtained from the just started laser scanning activity that allowed to obtain precious architectural information useful not only from the cultural heritage point of view but also for more operative and powerful tools, such as building information modelling, where all the information can be transferred later.

Keywords: BIM, integrated safety system, integrated security system, Internet of Everything, Internet of Things, laser scanning, safety management, security management.
\end{abstract}

\section{INTRODUCTION}

The Papal Basilica and the Sacred Convent of Saint Francis in Assisi in Italy represents a unique and peculiar cultural heritage site, where the mortal remains of Saint Francis are housed since 1230 A.D.

Millions of pilgrims and visitors coming from all over the world visit this site each year that, from 2000 A.D., together with other Franciscan sites in the surrounding and the whole Assisi town, have been appointed as World Heritage by UNESCO.

Peculiar, unique and complex cultural heritage sites, such as the considered one, need a great effort to ensure visitors security and safety, cultural heritage preservation and protection and great usability for pilgrims/visitors with particular reference to pilgrims/visitors with disabilities and for all the people and personnel normally present for the site management, including the community of Minor Conventual Friars that lives there. 
This goal can be reached using integrated systems [1-5] and new technologies, such as Internet of Everything (IoE), which allows to connect people, things (mobile terminals, smart sensors, device, actuators, wearable devices, etc.), data/information/knowledge and processes to reach the desired goals $[6,7]$.

The IoE system must be able to implement and support an integrated multidisciplinary model for security and safety management (IMMSSM) [8] for the specific, peculiar and unique context, using a multidisciplinary approach whose scheme is shown in Figure 1.

The IMMSSM is based on the following points:

1. Risk analysis (qualitative, semi-quantitative, quantitative and mixed including human factors) which is necessary to let all the threats be individuated and evaluated [9-12].

2. Impact analysis which is necessary to evaluate the damages generated by the threats individuated by means of risk analysis of the previous point.

3. Risk mitigation which is necessary to reduce both probabilities and damages of risks.

4. Residual risks management which is necessary to manage critical events after that risks take place despite the mitigation action of the previous point.

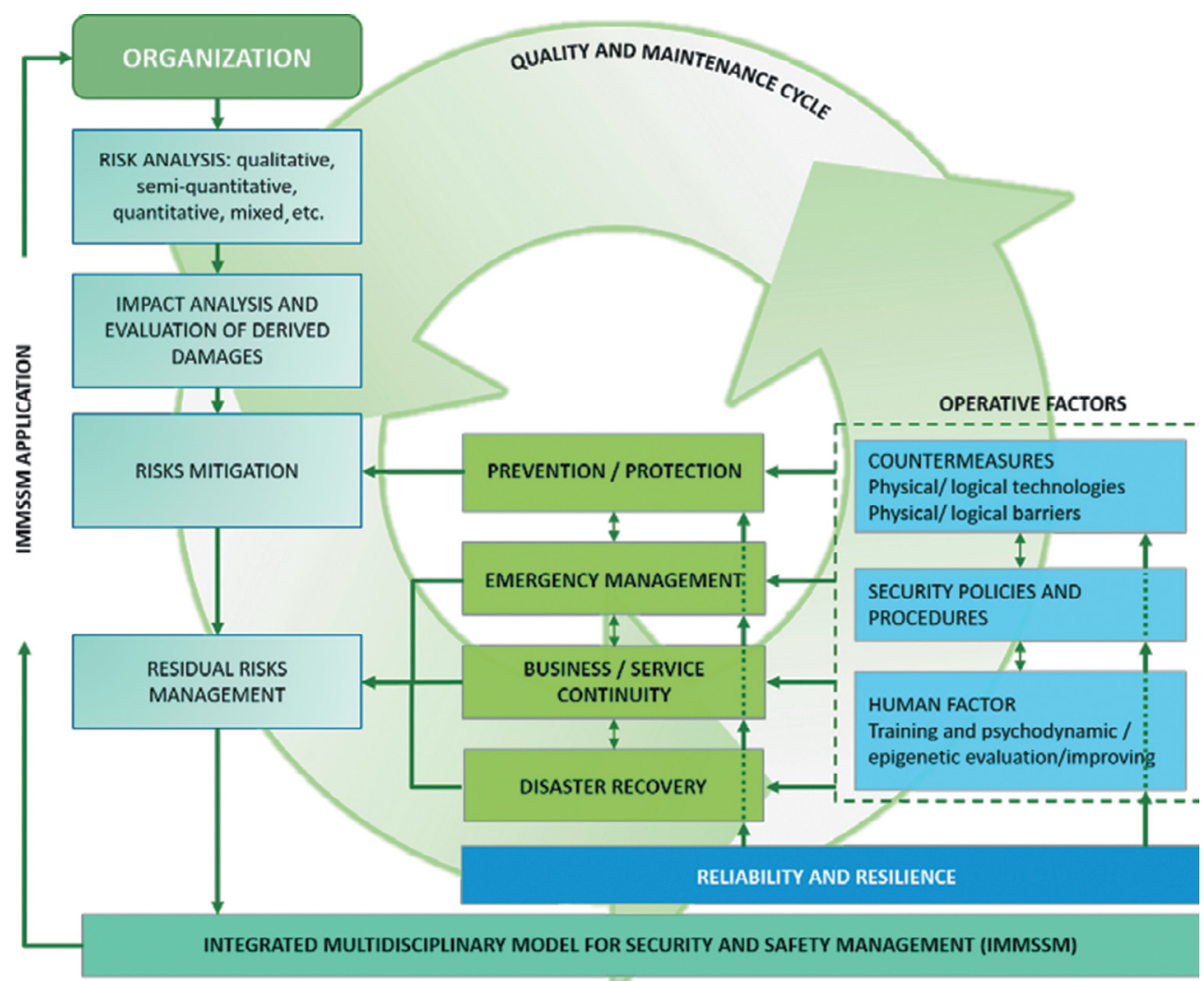

Figure 1: Scheme of the integrated multidisciplinary model for security and safety management (IMMSSM). 
Risks mitigation can be performed using fundamental operative factors or tools (OTs) which are represented by

1. Countermeasures: physical/logical technology, and physical/logical barriers [13].

2. Security policies and procedures, considering also human factor and psychological aspects [14].

Residual risk management can be done using fundamental tools, aided by OTs, which are represented by:

1. Emergency management.

2. Service and business continuity.

3. Disaster recovery.

The IMMSSM can be implemented and supported using a proper Integrated Technological System Framework based on IoE (IoE-ITSF) which allows the full functionalities of the IMMSSM with high flexibility and modularity. In this way, it is possible to translate any eventual modification of the IMMSSM into a fast and low-cost modification of the ITSF at any time, ensuring always the best performances of IMMSSM.

The general scheme of IoE-ITSF is shown in Figure 2.

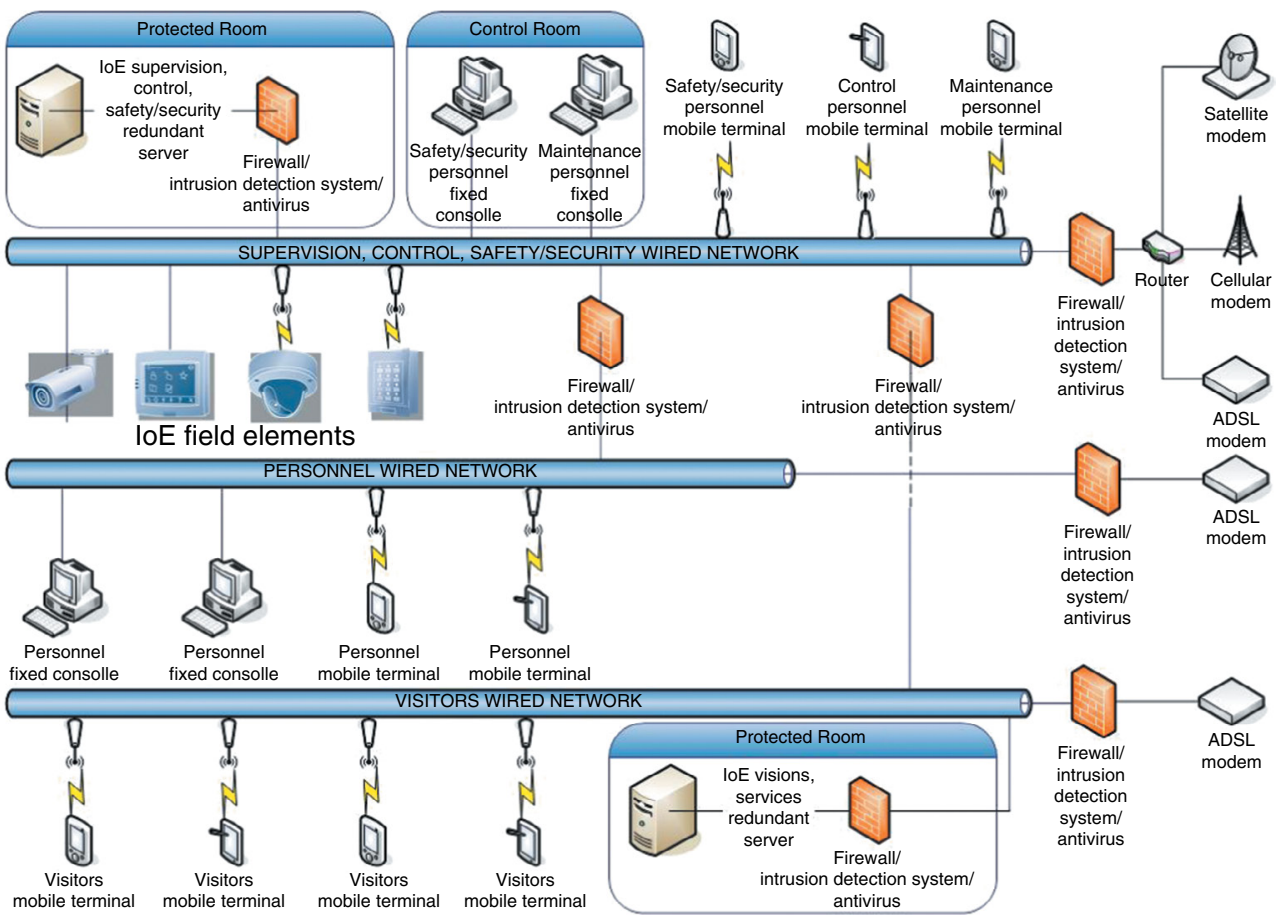

Figure 2: Scheme of the IoE-based Integrated Technological System Framework (IoE-ITSF) to support the integrated multidisciplinary model for security and safety management (IMMSSM). 
Due to the presence of strong architectural vincula, it is necessary to take particular care in wires and devices installation [15] and, for this reason, all the information deriving from laser scanning becomes fundamental.

\section{THE PAPAL BASILICA AND THE SACRED CONVENT OF SAINT FRANCIS IN ASSISI}

The Papal Basilica and the Sacred Convent of Saint Francis in Assisi in Italy represents a unique and peculiar cultural heritage site where the mortal remains of St. Francis are housed since 1230 A.D.

Millions of pilgrims and visitors coming from all over the world visit this site each year that, from 2000 A.D., together with other Franciscan sites in the surrounding and the whole Assisi town, have been appointed as World Heritage by UNESCO (Figs. 3 and 4).

The Papal Basilica, where unique frescoes by Giotto and other famous painters are present, is composed by three stratified structures:

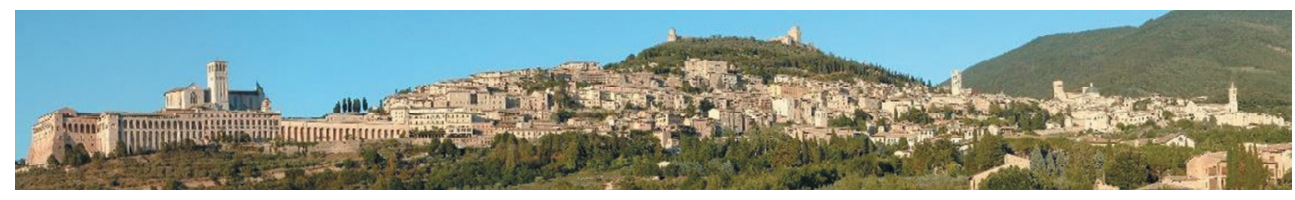

Figure 3: Panoramic view of Assisi.

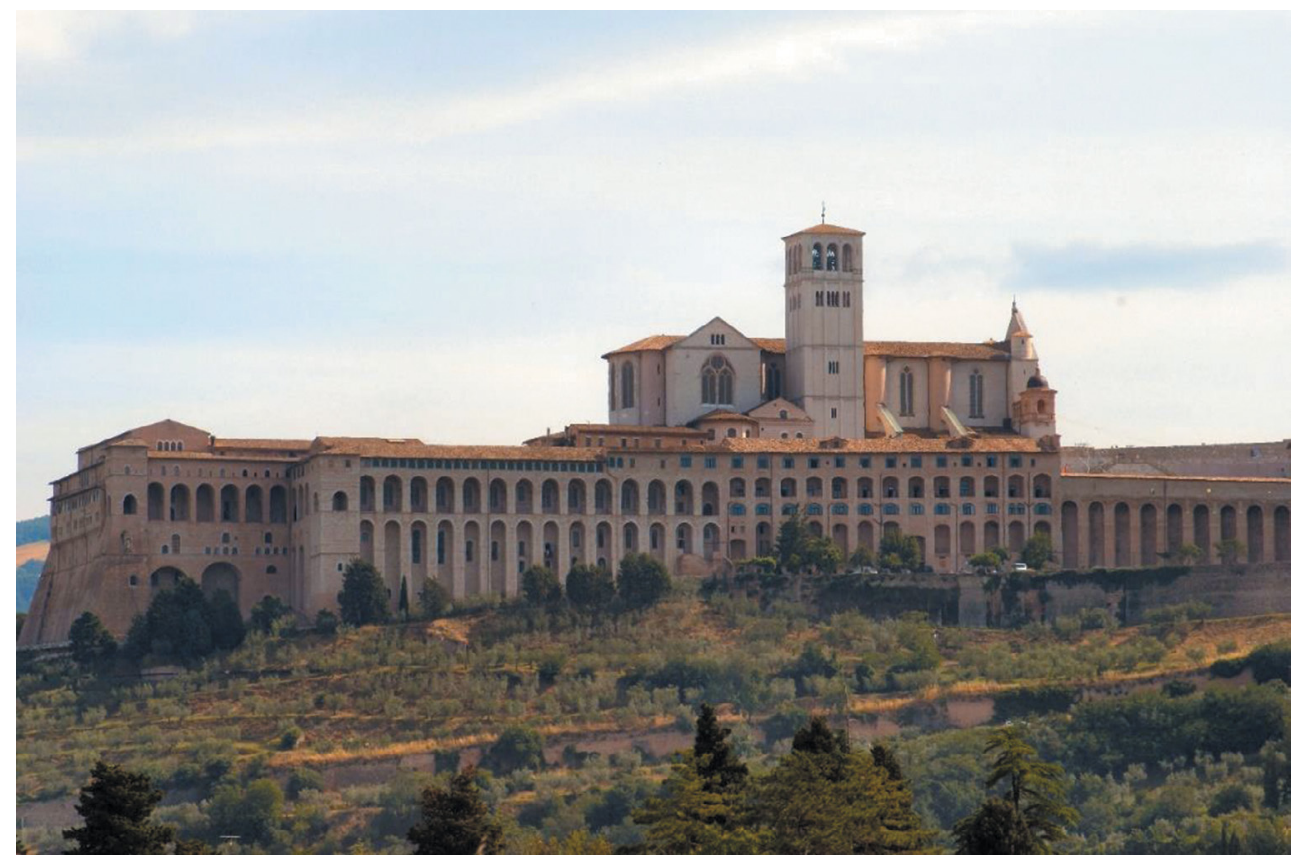

Figure 4: Panoramic view of the Papal Basilica and the Sacred Convent of Saint Francis in Assisi. 
1. The tomb of Saint Francis, located at the lower level

2. The lower Basilica, whose altar is just above the tomb of Saint Francis

3. The upper Basilica, located above the lower Basilica.

Inside the Sacred Convent are also present a museum, a library and a plenty of places where spiritual and cultural activities are hosted.

\section{THE LASER SCANNING ACTIVITY}

Even if all the 'classical' Geomatiques techniques can perfectly fulfil many crucial monument survey needs, there are still many cases where they show some limits. Most of the difficulties are related to the morphologic and architectural accessibility [16, 17].

To realize a three-dimensional (3D) model of the Basilica, an integrated technique survey activity was performed, preliminary planned on the basis of the available bi-dimensional maps (Fig. 5). In particular, measurements were performed using Global Navigation Satellite System (GNSS) receivers, topographic total stations (TLS), laser scanning and photogrammetry.

The control network used as reference system is represented by the UTM WGS84 ETRF2000 Datum as required by national legislation [18]. For this purpose, some points external to the Basilica have been surveyed using rapid static GNSS methodology. Starting from these points, different traverses were realized to branch out on the three upper levels of the Basilica (Figs. 6, 7 and 8). The definition of the vertices of the traverses station has been chosen as a function of the visibility of the laser targets and natural points to be measured. The latter activity is necessary for the subsequent alignment of laser scans and the subsequent geo-referencing of their data.

The TLS survey was performed only for the three main parts of the monumental complex: tomb (or crypt), the lower Basilica and the upper Basilica. Presently service and connection spaces were not surveyed.
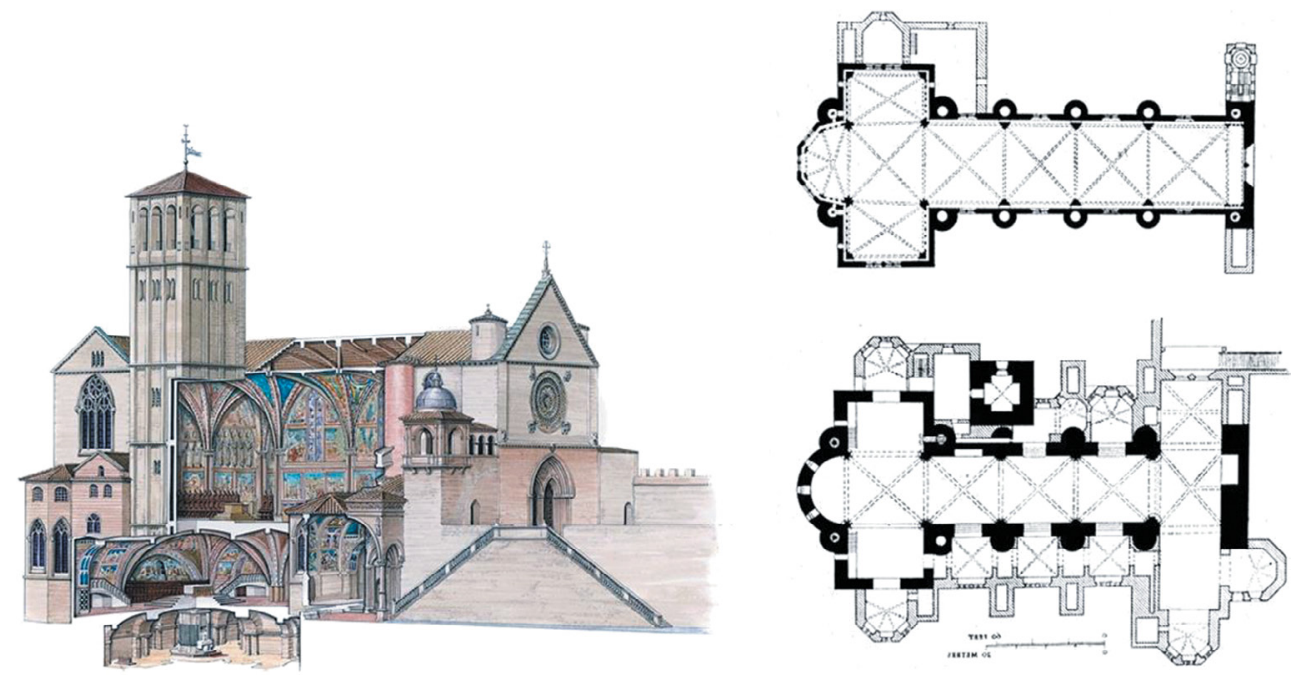

Figure 5: View of the three layers of the Basilica (left) and the related plants (up-right: higher Basilica, down-right: lower Basilica). 


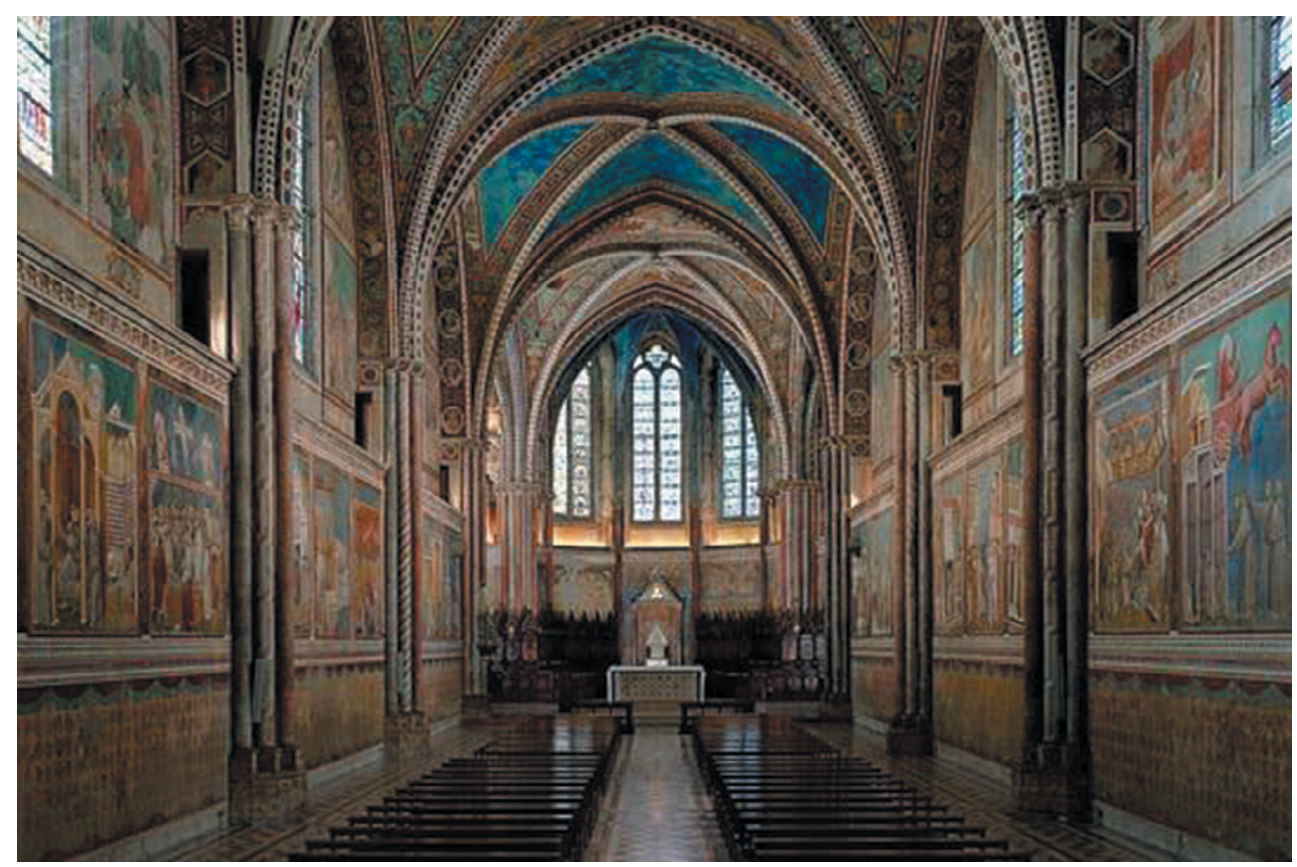

Figure 6: View of the interior of the upper Basilica where the Giotto's frescoes are visible.

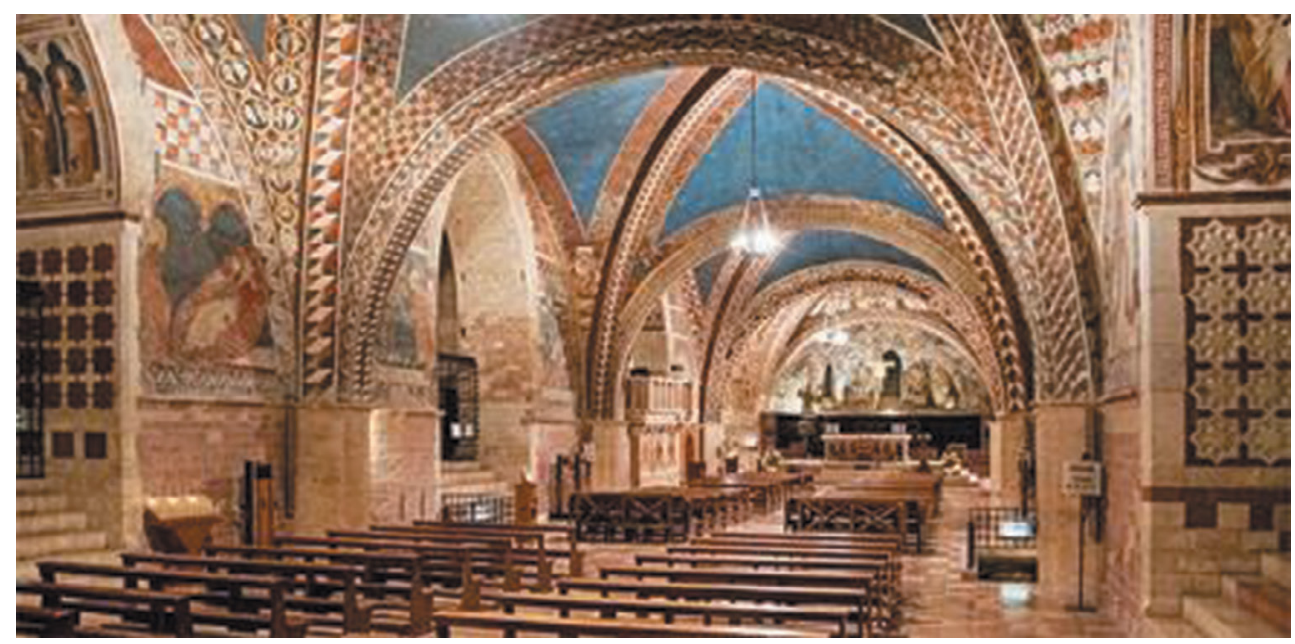

Figure 7: View of the interior of the lower Basilica.

To ensure the coverage of the above spaces and to minimize the shadow areas, a total of 33 laser acquisitions (Fig. 9) have been realized: 8 in the tomb, 18 in the lower Basilica (including the side chapels) and 7 in the upper Basilica.

The acquisition and the registration of the scans performed for the individual spaces have been realized by means of the Cyclone software, proceeding, at first, to the alignment between the different scans referring to each space and, subsequently, to their geo-referencing (Fig. 10). 


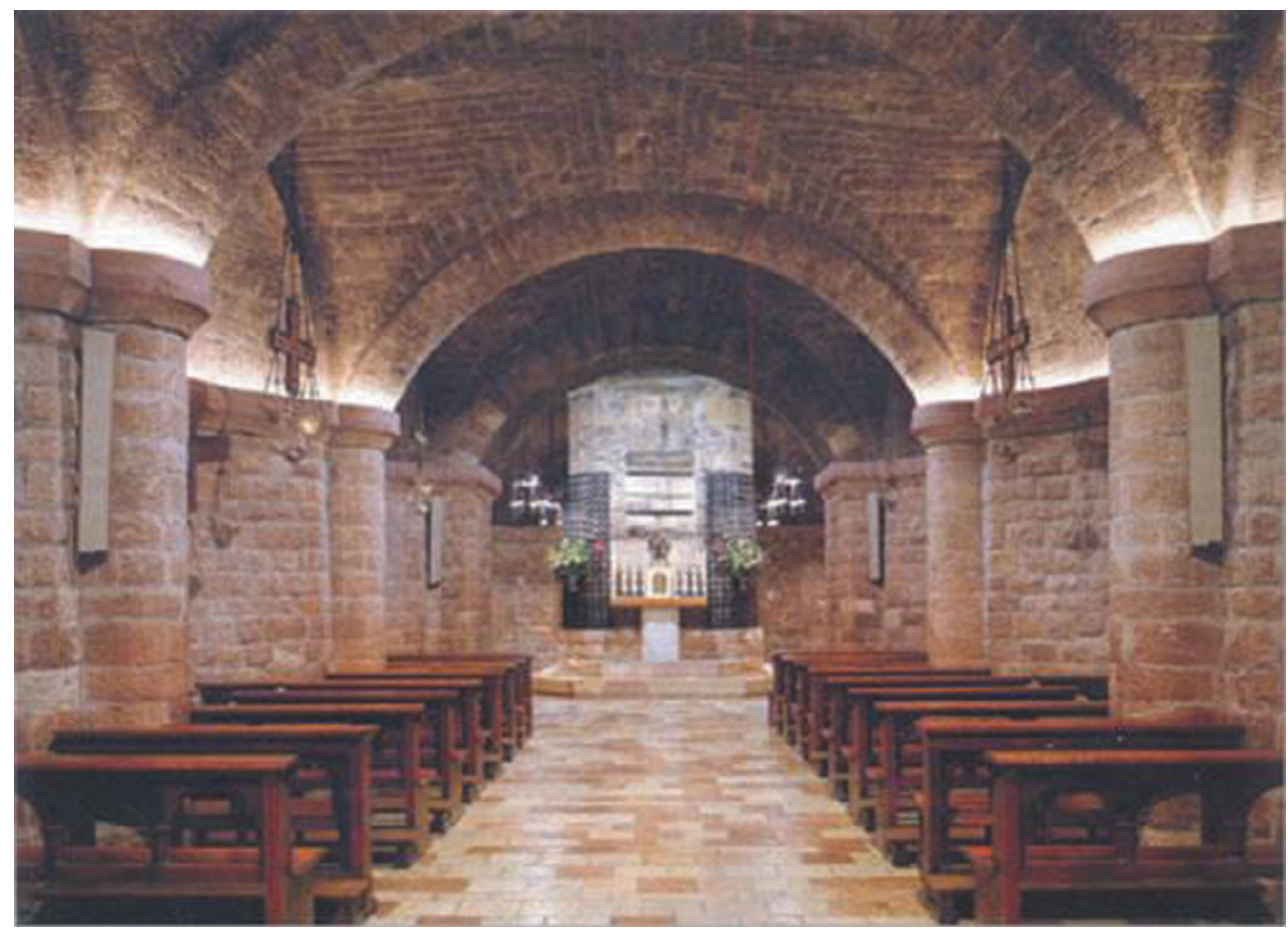

Figure 8: View of the tomb of Saint Francis.

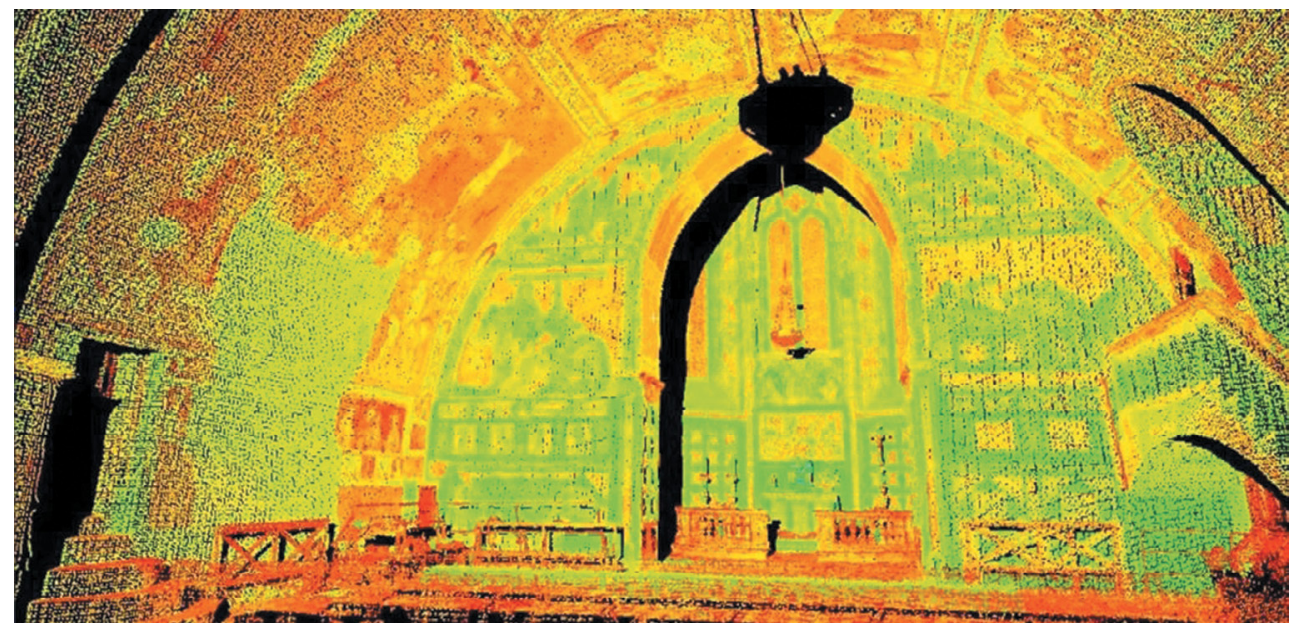

Figure 9: Example of a single scan.

In order to convert the point cloud into a final 3D model, it has been exported to $x y z$ and then imported into 'Geomagic' software format. A pre-processing of the cloud was performed by applying some of the filters available in the software, in particular, those most closely related to the type of survey and it was later carried out the meshing process. To optimize the 

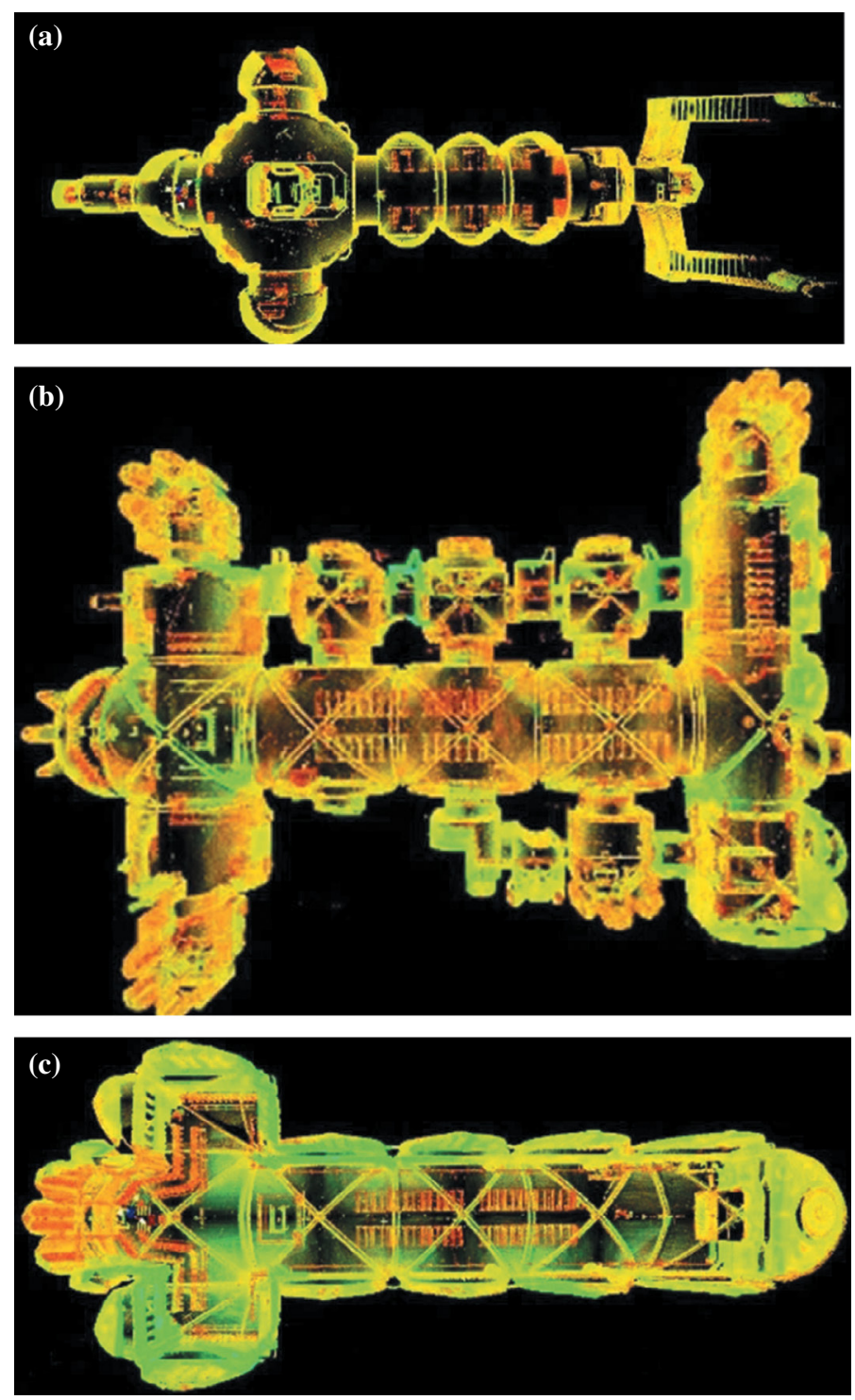

Figure 10: Point cloud: (a) tomb; (b) lower Basilica; and (c) upper Basilica.

results, the surface model was again filtered and, where possible, the 'closure of the holes' was performed (Fig. 11).

The models obtained were converted into several formats so as to export them in opensource or CAD software (Fig. 12).

To get two-dimensional (2D) representations (planimetric, transverse and longitudinal) and to obtain metrically correct maps, an experimental numerical algorithm, developed in $\mathrm{C}++$, has been used [19]. In particular, from the point cloud, infinitesimal portions have been selected, consistent with section planes, generating a set of $2 \mathrm{D}$ points converted later by a subsequent vectorialization algorithm and exported finally to '.dxf' format [19-21]. 

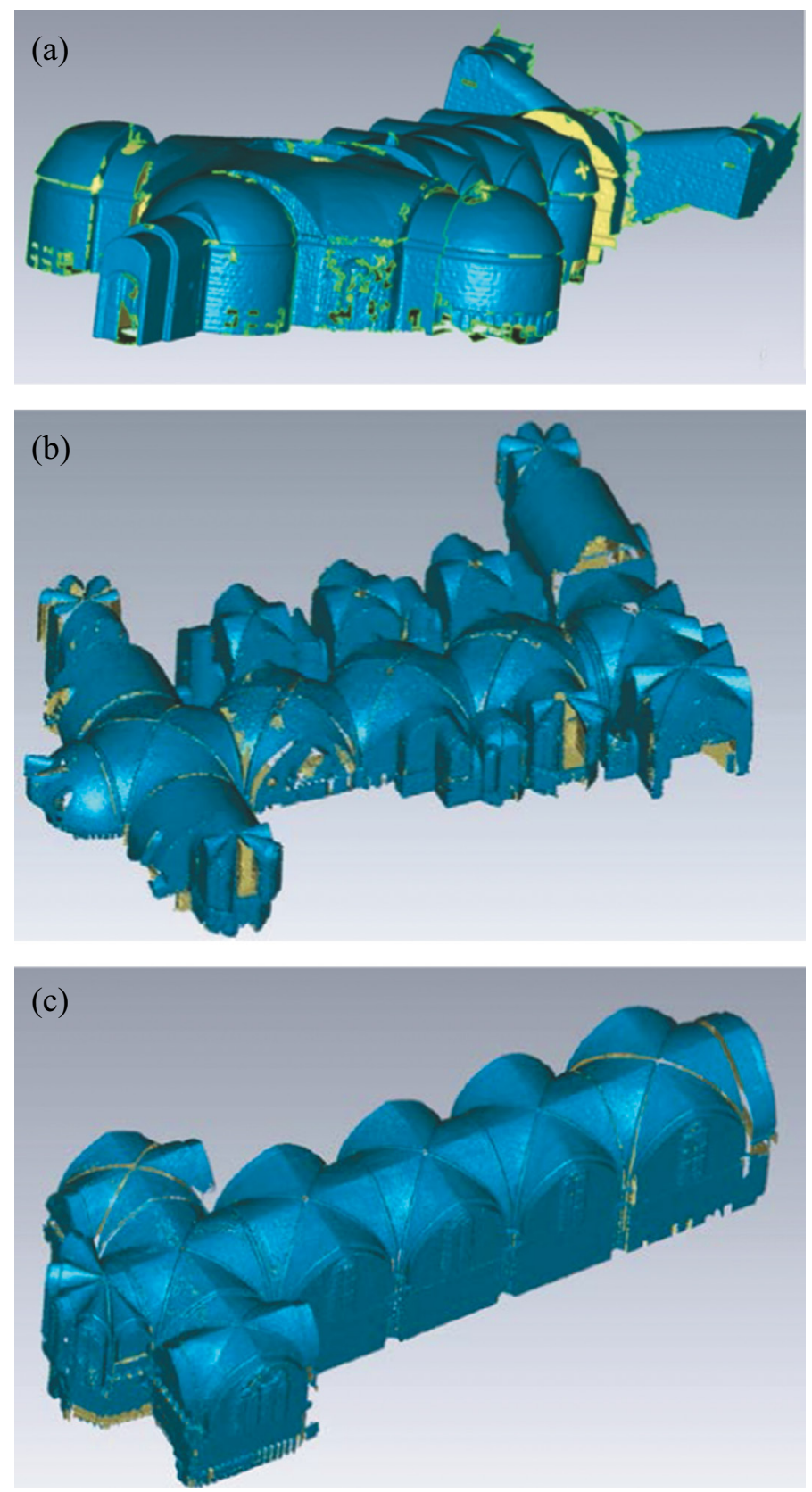

Figure 11: Meshing: (a) tomb; (b) lower Basilica; and (c) upper Basilica. 


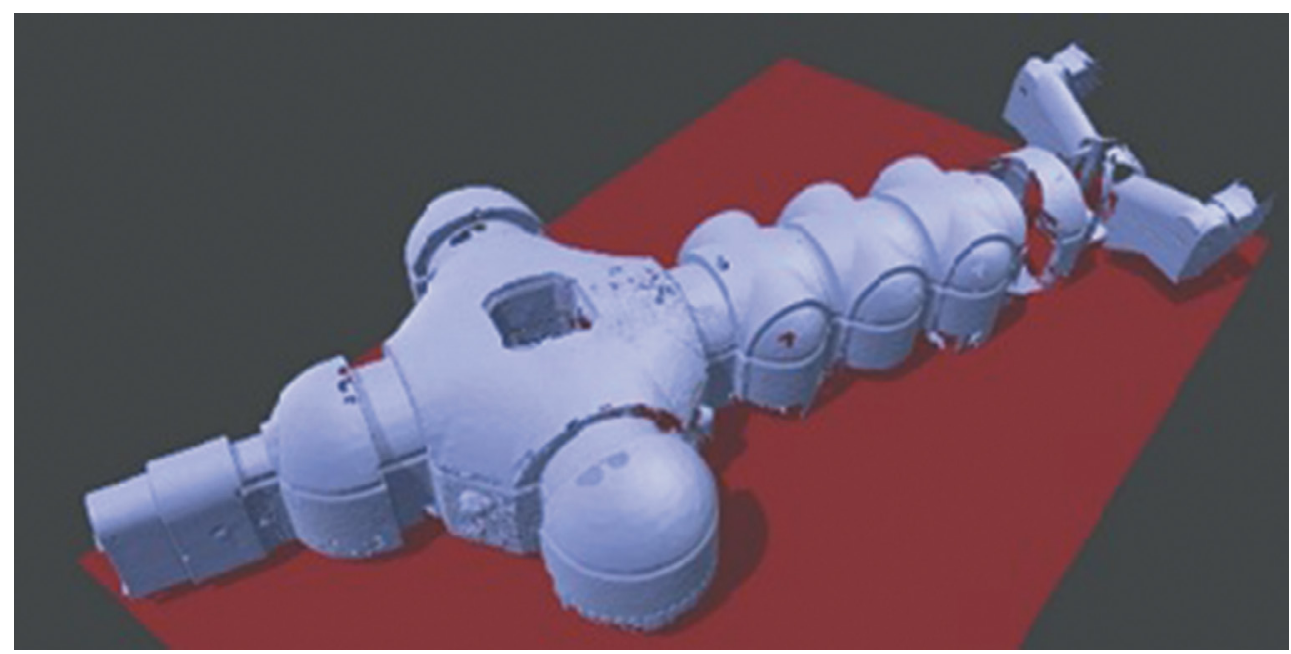

Figure 12: Representation of one of the models (the tomb, in this case) in an open-source environment.

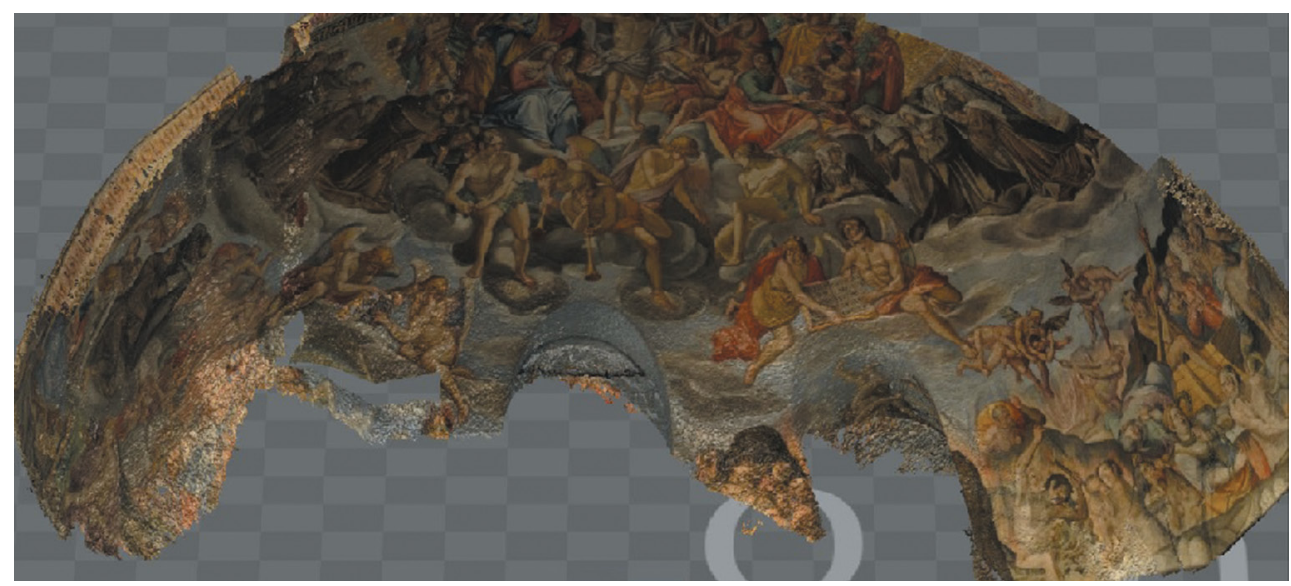

Figure 13: Example of a frescoes vault photogrammetric reconstruction.

The photogrammetric survey for 3D reconstruction of the frescoes was started, employing the Structure from Motion photogrammetric algorithms [22, 23]. An example is shown in Figure 13.

\section{RESULTS}

The first preliminary results are represented by the big amount of data obtained and the survey operations allowed to evidence critical points and correct procedures in such a complex cultural heritage site. Obviously, a big part of the work has still to be done to correctly manage and model the data, aimed at obtaining a complete geographic database as it's presently requested by the scientific technological community [22]. 


\section{CONCLUSIONS}

The methodology and the first results obtained from the just started laser scanning activity in the Papal Basilica and Sacred Convent of Saint Francis in Assisi have been illustrated.

They represent a fundamental activity that allows to obtain precious architectural information useful not only from the cultural heritage point of view but also for more operative and powerful tools, such as building information modelling, where all the information will be transferred later.

These subsequent activities are vital to create a proper IMMSSM, which allows for the consequent design and realization of the related IoE-ITSF that implements and supports it.

In this way, it will be possible to ensure a high level of pilgrims/visitors security and safety, cultural heritage preservation and protection and great usability for visitors with particular reference to pilgrims/visitors with disabilities and for all the people and personnel normally present for the site management, including the community of Minor Conventual Friars that lives there.

\section{REFERENCES}

[1] Garzia, F., Sammarco, E. \& Cusani, R., The integrated security system of the Vatican City State. International Journal of Safety \& Security Engineering, 1(1), pp. 1-17, 2011. DOI: 10.2495/SAFE-V1-N1-1-17.

[2] Contardi, G., Garzia, F. \& Cusani, R., The integrated security system of the Senate of the Italian Republic. International Journal of Safety \& Security Engineering, 1(3), pp. 219-246, 2011. DOI: 10.2495/SAFE-V1-N3-219-247.

[3] Garzia, F. \& Cusani, R., The integrated safety / security / communication system of the Gran Sasso mountain in Italy. International Journal of Safety \& Security Engineering, 2(1), pp. 13-39, 2012. DOI: 10.2495/SAFE-V2-N1-13-39.

[4] Garzia, F. \& Cusani, R., The safety/security/communication wireless LAN of the underground Gran Sasso mountain national laboratories of the Italian Institute of Nuclear Physics. International Journal of Safety \& Security Engineering, 2(3), pp. 209-226, 2012. DOI: 10.2495/SAFE-V2-N3-209-226.

[5] Garzia, F., Sammarco, E. \& Cusani, R., Vehicle/people access control system for security management in ports. International Journal of Safety \& Security Engineering, 2(4), pp. 351-367, 2012. DOI: 10.2495/SAFE-V2-N4-351-367.

[6] Garzia, F. \& Papi, L., An Internet of Everything based integrated security system for smart archaeological areas. Proceedings of the Fifty Annual IEEE International Carnahan Conference on Security Technology, Orlando, USA, pp. 64-71, 2016.

[7] Garzia, F. \& Sant'Andrea, L., The internet of everything based integrated security system of World War I Commemorative Museum of Fogliano Redipuglia in Italy. Proceedings of the Fifty Annual IEEE International Carnahan Conference on Security Technology, Orlando, USA, pp. 56-63, 2016.

[8] Garzia, F., An integrated multidisciplinary model for security management - Optimized implementation technique and related supporting technological system framework. Proceedings of the Fifty Annual IEEE International Carnahan Conference on Security Technology, Orlando, USA, pp. 107-114, 2016.

[9] Lombardi, M., Guarascio, M. \& Rossi, G., The management of uncertainty: Model for evaluation of human error probability in railway system. American Journal of Applied Sciences, 11(3), pp. 381-390, 2013. DOI: 10.3844/ajassp.2014.381.390. 
[10] Guarascio, M., Lombardi, M., Rossi, G. \& Sciarra, G., Risk analysis and acceptability criteria. WIT Transactions on the Built Environment, 94, pp. 131-138, 2007. DOI: 10.2495/SAFE070131.

[11] Guarascio, M., Lombardi, M. \& Massi, F., Risk Analysis in handling and storage of petroleum products. American Journal of Applied Sciences, 10(9), pp. 965-978, 2013. DOI: 10.3844/ajassp.2013.965.978.

[12] Broder, J. F. \& Tucker, E., Risk Analysis and the Security Survey, ButterworthHeinemann: New York, 2012.

[13] Garzia, F., Handbook of Communication Security, WIT Press, New York, USA, 2013.

[14] Borghini, F., Garzia, F., Borghini, A. \& Borghini, G., The Psychology of Security, Emergency and Risk, WIT Press, Southampton, UK, 2016.

[15] Garzia, F. \& Cusani, R., New technique for the optimization of security communication wired networks in historical buildings. Proceedings of the Fortieth Annual IEEE International Carnahan Conference on Security Technology, Medellin, Colombia, pp. 116-121, 2013.

[16] Costantino, D., Angelini, M.G. \& Mazzone, F., Integrated survey methodology for the crime reconstruction. Imaging Science Journal, 64(6), pp. 341-351, 2016. DOI: 10.1520/JFS11868J.

[17] Baiocchi, V., Dominici, D., Milone, M. V. \& Mormile, M., Development of a software to optimize and plan the acquisitions from UAV and a first application in a post-seismic environment. European Journal of Remote Sensing, 47(1), pp. 477-496, 2014. DOI: 10.2747/1548-1603.48.1.24.

[18] Barbarella, M., Digital technology and geodetic infrastructures in Italian cartography. Citta e Storia, 9(1), pp. 91-110, 2014. DOI: 10.17426/15275.

[19] Costantino, D. \& Angelini, M.G., Realization of a cartographic GIS for the filing and management of the archaeological excavations in the Nelson's Island. Lecture Notes in Computer Science, 6436 LNCS, pp. 513-527, 2010.

[20] Costantino, D., \& Angelini, M. G., Three-dimensional integrated survey for building investigations. Journal of Forensic Sciences, 60(6), pp. 1625-1632, 2015. DOI: 10.1111/1556-4029.12915.

[21] Costantino, D. \& Angelini, M.G., Process modelling and photogrammetric production for structural investigations concerning to the collapse of Palazzo Edilizia in Salerno (Italy). Lecture Notes in Computer Science, 7616 LNCS, pp. 440-448, 2012. DOI: https://doi.org/ 10.1007/978-3-642-34234-9_45.

[22] Costantino, D., Angelini, M.G. \& Caprino, G., Laser scanner survey of an archaeological site - Scala di furno (Lecce, Italy). International Archives of the Photogrammetry, Remote Sensing and Spatial Information Sciences, 38(5), pp. 178-183, 2010. DOI: https://doi.org/ 10.1007/978-3-319-60928-7_24.

[23] Costantino, D., Angelini, M.G. \& Milan N., 3D documentation and visualization of cultural heritage. XXIII International CIPA Symposium, Prague, 12-16 September 2011 (Best Poster Paper Award), vol. CD ROM, ISBN: 978-80-01-04885-6. 